\title{
The relation between unpalatable species, nutrients and plant species richness in Swiss montane pastures
}

\author{
DAVID KLEIJN ${ }^{1,2, *}$ and HEINZ MÜLLER-SCHÄRER ${ }^{1}$ \\ ${ }^{1}$ Department of Biology, Unit of Ecology \& Evolution, University of Fribourg, Chemin du Musée 10, \\ CH-1700 Fribourg, Switzerland; ${ }^{2}$ Present address: Nature Conservation and Plant Ecology Group, \\ Wageningen University, Bornsesteeg 69, 6708 PD Wageningen, The Netherlands; *Author for \\ correspondence (e-mail: David.Kleijn@wur.nl; phone: ++31-317-483883; fax: ++31-317-484845)
}

Received 13 December 2004; accepted in revised form 9 September 2005

Key words: Grassland, Nutrients, Total soil N:P ratio, Veratrum album

\begin{abstract}
In agriculturally marginal areas, the control of unpalatable weeds on species rich pastures may become problematic due to agricultural and socio-economic developments. It is unclear how increased dominance of unpalatable species would affect the botanical diversity of these grasslands. We investigated whether there was any relationship between plant species diversity and the abundance of unpalatable species and whether soil conditions affected this relationship. In three species-rich montane pastures in western Switzerland, we related plant species richness to soil attributes, the relative cover of all unpalatable species and the relative cover of the locally dominant, toxic Veratrum album in 25 plots of $4 \mathrm{~m}^{2}$. We furthermore determined species richness in small transects through patches of $V$. album. Species richness was significantly lower in and near $(\leq 0.3 \mathrm{~m}$ ) patches of $V$. album. At the field scale, plant species richness was best described by total soil N:P ratio (positive relation) in one site and the relative abundance of unpalatable species (negative relation) and soil N:P ratio (positive relation) in a second site. In the third site, species richness was not significantly related to any measured variable. Vegetation diversity (Simpson's $D$ ) was negatively related to the relative abundance of unpalatable species in one site and positively related to $\mathrm{pH}$ in another site. The results suggest that no single factor can explain plant species richness and diversity in montane pastures. At very high densities unpalatable species can have adverse effects but soil nutrient status appears to be a more general determinant of plant species richness. Conservation efforts should give priority to the prevention of intensification of these pastures.
\end{abstract}

\section{Introduction}

Agriculturally marginal areas in Central and Eastern Europe, the Mediterranean and mountain ranges in Western Europe, are the last strongholds of European farmland biodiversity (Donald et al. 2001, 2002; EEA 2004). Currently, also in these areas the trend can be observed that land-use on the more productive fields is being intensified while many unproductive fields are being abandoned (MacDonald et al. 2000). Both developments have pronounced negative effects on biodiversity. Currently, European policy makers are giving agricultural subsidies increasingly for landscape maintenance and biodiversity conservation instead of giving direct price support (e.g. UN/ECE 2003). 
Subsidies for agri-environment schemes and less favoured areas therefore form an important tool to maintain traditional extensive farming practices and the associated biodiversity. In pastures, weed control may become a problem as agri-environment schemes usually prohibit the use of herbicides. Traditionally all species that are unpalatable to livestock are considered weeds and dominant species were controlled mechanically or even by hand by farmers aiming to maintain forage quality (Ammon and Müller-Schärer 1999). Even with subsidies, labour costs are becoming too high to control weeds in such a way, particularly on sites that are difficult to access such as high altitude summer grazing grounds or pastures on slopes. Weeds are therefore increasingly left uncontrolled and may be able to spread. While this has clear undesirable consequences for fodder quality, it is unclear what the consequences are for grassland diversity.

Large grazers consume plants selectively, preferring palatable to unpalatable species. Selective grazing may therefore lead to competitive dominance of a few unpalatable species at the expense of many palatable species, resulting in a decrease of plant species richness. However, effects of grazers on plant species composition depend on grazing intensity and fertility of the habitat (Proulx and Mazumder 1998). Under conditions of high nutrient supply, the high regrowth capacity of many palatable species after defoliation is often sufficient to compete successfully with less palatable species that have not been defoliated (Berendse and Elberse 1989; Augustine and MacNaughton 1998). Additionally, nutrient supply itself has pronounced effects on plant species richness (Janssens et al. 1998; Braakhekke and Hooftman 1999).

Increases in the abundance of unpalatable plant species following an increase in grazing pressure have often been documented (Grant et al. 1985; Augustine and McNaughton 1998; Edwards and Crawley 1999), but simultaneous decreases in plant species richness have rarely been observed (e.g. Gough and Grace 1998; Todd and Hoffman 1999). Many grassland plants are long-lived and it may therefore take a long time before the effects of experimental treatments are reflected in vegetation composition and species richness (Schläpfer and Fischer 1998). An alternative approach is to study vegetation patterns in grasslands that have been grazed for long periods of time. Here the effects of unpalatable species and soil nutrient status on species richness should be reflected in patterns in the vegetation.

The central aim of this study was to determine whether (1) plant species richness of montane grasslands is negatively related to the abundance of unpalatable plant species, (2) plant species richness is related to soil nutrient supply and (3) the effects of unpalatable species on species richness depend on the level of soil nutrient supply. We examined the effects of unpalatable species as a functional group. Additionally, we examined the effects of Veratrum album L. (Liliales, Melanthiaceae) in more detail as this was a particularly abundant unpalatable species at the study sites. This may provide more insights into the mechanisms that lead to the observed relationships. 


\section{Methods}

\section{Field sites}

We selected three montane grasslands in Western Switzerland. Sites were selected that were species-rich but also had considerable spatial variation in the density of unpalatable plant species. Distance from the farm building may be an important determinant for the abundance of unpalatable weed species (Spatz 1980). Thus study sites were chosen to be at approximately similar distances (400-800 m) from the farm. The first site, La Petite Ronde, was located near Les Verrieres, in the South Jura Mountains ( $46^{\circ} 56^{\prime} \mathrm{N}, 6^{\circ} 27^{\prime} \mathrm{E}$; $1130 \mathrm{~m}$ a.s.1.). The field was located on a moderate, West-facing slope. The vegetation was dominated by Festuca rubra, Cynosurus cristatus, Veratrum album and Ranunculus tuberosus, included characteristic sub-ordinate species such as Dactylorhiza maculata, Euphorbia verrucosa, Narcissus poeticus and Polygala serpyllifolia, and was used for grazing by calves and other non-lactating cattle. The field had been fertilized moderately for some time up to approximately 1990 . The second field, Gross Rüggli, was located near Jaun in the Pre-Alps (46 $36^{\prime}$ N, $7^{\circ} 16^{\prime} \mathrm{E}$; $1310 \mathrm{~m}$ a.s.l.) on an East-facing slope. The vegetation, dominated by Cynosurus cristatus, Festuca pratensis, F. rubra, Cirsium oleraceum and Alchemilla vulgaris, interspersed by sub-ordinate species like Carex tomentosa, Coeloglossum viride, Colchicum autumnale, Crepis aurea, Dactylorhiza maculata and Orchis mascula, was used to graze dairy cattle. To our knowledge, the field had never been fertilized. The third field, Spittel Gantrisch, was located near Sangernboden in the Pre-Alps $\left(46^{\circ} 40^{\prime}, 7^{\circ} 22^{\prime}, 1340 \mathrm{~m}\right.$ a.s.1.) on a North-Northwest facing slope. Festuca rubra, Agrostis capillaris, Polygonum bistorta and Veratrum album dominated the vegetation. Typical sub-ordinate species were Carex brizoides, C. ferruginea, Gymnadenia conopsea, Myosotis scorpioides, Pedicularis foliosa, Plantago atrata, Soldanella alpina and Traunsteinera globosa. The field was used to graze dairy cattle and, to our knowledge, had never been fertilized. Soils of all three fields were dystric cambisols on calcareous bedrock. La Petite Ronde and Gross Rüggli were sampled from 8 to 12 June 1999 and 19 June-1 July 1999, respectively. Spittel Gantrisch was sampled from 8 to 14 June 2000.

\section{Vegetation sampling}

In each field, we established $252 \times 2 \mathrm{~m}$ plots at random locations inside an area of approximately $50 \times 50 \mathrm{~m}$. In each plot, we determined species cover by means of a point-quadrat method. A $3 \mathrm{~mm}$ thick needle was placed 50 times in the vegetation at approximately regular intervals inside the $4 \mathrm{~m}^{2}$ plots and each time all species in contact with the needle were scored. Percentage cover of a species was subsequently calculated as the number of hits times two. Species that were not hit by the needle were noted as species without cover. 
Veratrum album is a long-lived clonal species that is toxic due to high concentrations of alkaloids. In pastures, it usually grows in conspicuous tight patches of up to $15, \mathrm{ca} .60 \mathrm{~cm}$ tall shoots that often belong to the same genet (Kleijn and Steinger 2002). Adult shoots consist of up to 15, approximately $25 \mathrm{~cm}$ long, broadly elliptical leaves on a 'stem' consisting of the leaf sheaths. Cattle avoid the conspicuous shoots of Veratrum and grazing promotes the vegetative lateral expansion of genets which contributes to the local dominance of the species. For a more detailed account of the life history of Veratrum see Schaffner et al. (2001) and Kleijn and Steinger (2002). To examine small-scale effects of Veratrum in our fields we established 20 transects in each field. A transect started inside a Veratrum patch and extended $70 \mathrm{~cm}$ (approximately the height of Veratrum shoots) outside the patch. Each transect consisted of two $10 \times 10 \mathrm{~cm}$ sub-plots inside and seven sub-plots outside the patch. In each sub-plot, presence of all species was noted.

\section{Soil sampling}

After the vegetation composition of all $252 \times 2 \mathrm{~m}$ plots had been determined, we collected soil samples in each plot by taking $8,2.5 \mathrm{~cm}$ diameter soil cores, either $30 \mathrm{~cm}$ deep or until solid rock was hit, thus sampling all available rooting space. The eight cores were pooled to yield one sample per plot. The samples were transported to the laboratory in a cool-box where they were initially stored at $4{ }^{\circ} \mathrm{C}$ until being processed. Time between collection and processing of the samples was never more than $24 \mathrm{~h}$. The $10 \times 10 \mathrm{~cm}$ plots were not sampled for soil nutrients.

All soil samples were thoroughly mixed and fragments of rock and roots were removed by sieving using a $5 \mathrm{~mm}$ mesh. A sub-sample of $10 \mathrm{~g}$ was used to determine water content by drying for $48 \mathrm{~h}$ at $80{ }^{\circ} \mathrm{C}$. A fresh sub-sample of $20 \mathrm{~g}$ was suspended in $50 \mathrm{ml} 1 \mathrm{Mol} \mathrm{KCl}$, left shaking for an hour, filtered and stored at $-20{ }^{\circ} \mathrm{C}$ until available nitrogen $\left(\mathrm{NO}_{3}+\mathrm{NH}_{4}\right)$ was analyzed. Total amounts of $\mathrm{N}$ and $\mathrm{P}$ in the soil samples were determined on air-dried sub-samples after digestion with $\mathrm{H}_{2} \mathrm{O}_{2}$ at $100{ }^{\circ} \mathrm{C}$, followed by digestion with concentrated sulphuric acid at $300{ }^{\circ} \mathrm{C}$ under the influence of selenium as a catalyst (Houba and Van der Lee 1995). Salicylic acid was added to prevent the loss of nitrate. Both available $\mathrm{N}$ and total $\mathrm{N}$ and $\mathrm{P}$ were measured spectrophotometrically using a segmented flow analyzer (Skalar SAN ${ }^{\text {plus }}$ System, Skalar, Breda, The Netherlands). Soil $\mathrm{pH}-\mathrm{H}_{2} \mathrm{O}$ was measured on a sub-sample of $5 \mathrm{~g}$ air-dried soil solved in $12.5 \mathrm{ml}$ $\mathrm{H}_{2} \mathrm{O}$ using a WTW pH 525 (Retsch, Weilheim, Germany). All soil analyses were carried out at Wageningen University, Wageningen, The Netherlands.

\section{Analysis}

Palatability of a given species is a relative trait: the consumption of an unpalatable species depends on the palatability of the species in the immediate 
vicinity and the type and density of the herbivores present. Nevertheless, for simplicity we classified species into a palatable and an unpalatable group following Doree (1987), Ammon and Müller-Schärer (1999) and Lauber and Wagner (1998) and determined the relative abundance of unpalatable species (calculated as the number of hits of unpalatable species divided by the total number of hits per plot).

We used Stepwise Multiple Linear Regression with forward selection to determine what explanatory variables (Field, N-available, N-total, P-total, total soil $\mathrm{N}: \mathrm{P}$ ratio, $\mathrm{H}_{2} \mathrm{O}$-content, $\mathrm{pH}$, cover of unpalatable species, cover of Veratrum album) best described plant species richness and diversity (Simpson's index, $D$ ) in the $752 \times 2 \mathrm{~m}$ plots. Two-way interactions were considered only when the two factors making up the interaction were already in the model.

We used one-way ANOVA to test for effects of position within the smallscale transect on species numbers in each field. Significant position effects revealed by the ANOVA were followed by a sequential Dunn-Šidák test (Sokal and Rohlf 1995) to determine what position deviated significantly from that of the outer-most position at $60-70 \mathrm{~cm}$ from the Veratrum patch.

Prior to all analyses normality of the distribution of the data was examined and residuals were plotted vs. fitted values to test for constancy of variance of the errors. If variance increased with increasing values of the response variate, ln-transformed data were used in the analyses.

\section{Results}

\section{Characterization of the field sites}

The range in (a-)biotic conditions encountered in the three field sites are given in Table 1. The La Petite Ronde site was more nutrient-poor and little variation was observed, particularly in total $\mathrm{N}$ and $\mathrm{P}, \mathrm{pH}$ and the abundance of unpalatable species, compared to the other two sites. The range in species numbers per plot was roughly similar at the three sites.

Table 1. The range in observed biotic and abiotic variables determined in three montane pastures.

\begin{tabular}{lllllllll}
\hline Pasture & $\mathrm{N}_{\mathrm{av}}$ & $\mathrm{N}_{\text {tot }}$ & $\mathrm{P}_{\text {tot }}$ & $\mathrm{pH}\left(\mathrm{H}_{2} \mathrm{O}\right)$ & $\mathrm{H}_{2} \mathrm{O}(\%)$ & unpal. & V.a. & No. spec. \\
\hline La Petite Ronde & $19-52$ & $2.3-3.1$ & $0.38-0.55$ & $5.13-5.70$ & $30.3-33.5$ & $0.07-0.30$ & $0-0.24$ & $21-50$ \\
Gross Rüggli & $45-105$ & $5.7-11.7$ & $0.77-1.37$ & $6.20-7.40$ & $41.1-56.3$ & $0.11-0.50$ & $0-0.10$ & $24-51$ \\
Spittel Gantrisch & $17-38$ & $4.4-6.7$ & $0.72-1.18$ & $4.38-6.11$ & $40.5-45.5$ & $0.13-0.59$ & $0-0.17$ & $26-64$ \\
\hline
\end{tabular}

$\mathrm{N}_{\mathrm{av}}$, available nitrogen $\left(\mathrm{mg} / \mathrm{kg}\right.$ dry soil); $\mathrm{N}_{\text {tot }}$ and $\mathrm{P}_{\text {tot }}$, total nitrogen and phosphorus respectively (g/kg dry soil); $\mathrm{H}_{2} \mathrm{O}$, soil water content (\%); unpal., relative cover of unpalatable species (proportion); V.a., relative cover of Veratrum album (proportion), No. spec., number of species $\left(4 \mathrm{~m}^{2}\right)$. 
Table 2. Best models predicting plant species richness and Simpson's diversity Index (D). Models selected with Multiple Linear Regression and stepwise forward selection.

\begin{tabular}{|c|c|c|c|}
\hline Response variable & Model & $R_{\text {model }}^{2}$ & $p_{\text {model }}$ \\
\hline \multicolumn{4}{|l|}{ La Petite Ronde } \\
\hline Species richness: & - & & \\
\hline Simpson's $D$ : & - & & \\
\hline \multicolumn{4}{|l|}{ Gross Rüggli } \\
\hline Species richness: & $10.59+3.96 \bullet \mathrm{N} / \mathrm{P}_{\text {ratio }}^{* * *}$ & 41.2 & $<0.001$ \\
\hline Simpson's $D$ : & $-20.7+5.35 \bullet \mathrm{pH}^{*}$ & 19.8 & 0.015 \\
\hline \multicolumn{4}{|l|}{ Spittel Gantrisch } \\
\hline Species richness: & $0.30-39.23 \bullet$ prop. unpalatable plants ${ }^{* * *}+8.84 \bullet \mathrm{N} / \mathrm{P}_{\text {ratio }}{ }^{* *}$ & 65.2 & $<0.001$ \\
\hline Simpson's $D$ : & $24.48-24.95 \bullet$ prop. unpalatable plants ${ }^{* * *}$ & 54.4 & $<0.001$ \\
\hline
\end{tabular}

Significance of terms indicated by asterisks, ${ }_{p}^{*}<0.05, \stackrel{* *}{p}<0.01, \stackrel{* * *}{p}<0.001 . R^{2}=$ adjusted $R^{2}$ statistic (GENSTAT 1993).

\section{Larger-scale relationships}

We found significant interactions between the effects of 'Field' and a number of the other factors. We therefore analyzed the data of each field separately. Plant species richness was best described by different models in the three fields (Table 2). In the Gross Rüggli site, plant species richness was positively related to N:P ratio (Table 2, Figure 1a). In the Spittel Gantrisch site, plant species richness was best explained by a combination of N:P ratio and the abundance of unpalatable species (Figure 1). Plant species richness was not significantly related to any factor in the La Petite Ronde site.

Simpson's index of diversity $(D)$ was best described by a positive relationship with $\mathrm{pH}$ in the Gross Rüggli site and a negative relationship with the abundance of unpalatable species in the Spittel Gantrisch site (Table 2, Figure 2). As with the species richness, Simpson's $D$ was not significantly related to any factor in the La Petite Ronde site.

In none of the three sites did we find a significant interaction between the effects of unpalatable species and soil nutrient supply suggesting that in the study sites, the effects of unpalatable species did not depend on the level of soil nutrient supply. In none of the three field sites was the abundance of Veratrum significantly related to plant species richness, not even when it was related as the single factor explaining plant species richness.

\section{Small-scale relationships}

We found a significant interaction between the effects of fields and the position relative to the Veratrum patch on small-scale plant species richness. This indicates that patterns in species richness near Veratrum patches differed between fields. Separate analyses for the three fields subsequently showed that in the Gross Rüggli and Spittel Gantrisch sites plant species richness was significantly 

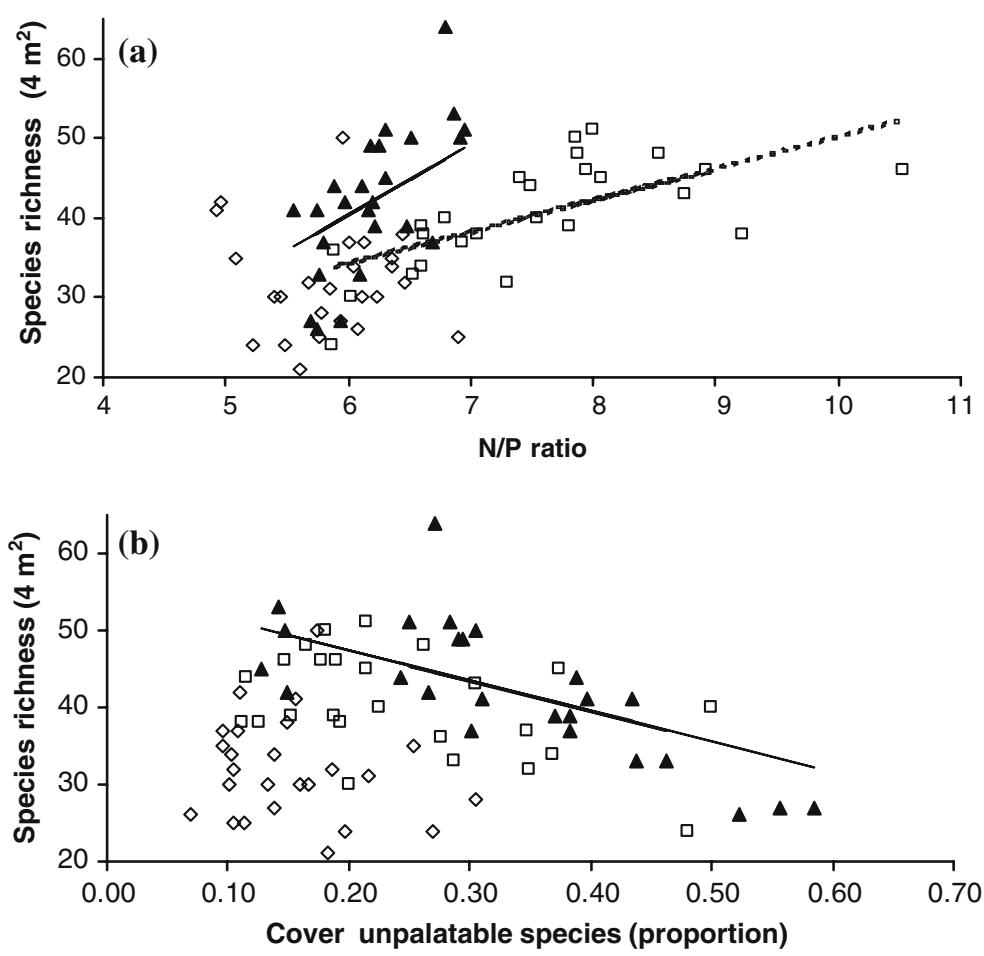

Figure 1. Relationship between plant species richness of montane grasslands and (a) total soil N:P ratio and (b) the abundance of unpalatable species. Diamonds, La Petite Ronde; squares and dashed line, Gross Rüggli; triangles and solid line, Spittel Gantrisch. Regression lines for significant relationships only, as given in Table 2. For regression models with two predictors, regression lines for one predictor were drawn at a fixed value (mean) of the second predictor.

reduced below, and up to a maximum distance of $30 \mathrm{~cm}$ from, Veratrum patches (Figure 3). Maximum reduction amounted to approximately $25 \%$ of the species numbers in the open pasture. In the La Petite Ronde site, no significant differences were found. Nevertheless, here the overall pattern across patches was similar to the other two sites and lack of a significant response may have been due to the relatively low mean species richness of the La Petite Ronde site. Analyzing the distribution of the most frequently encountered individual species did not reveal any consistent trends, indicating that interactions between Veratrum and other species were not species specific and did therefore not result in any changes in vegetation composition.

\section{Discussion}

We did not find a single factor that was significantly related to plant species richness or diversity in different montane pastures in Switzerland. Factors 

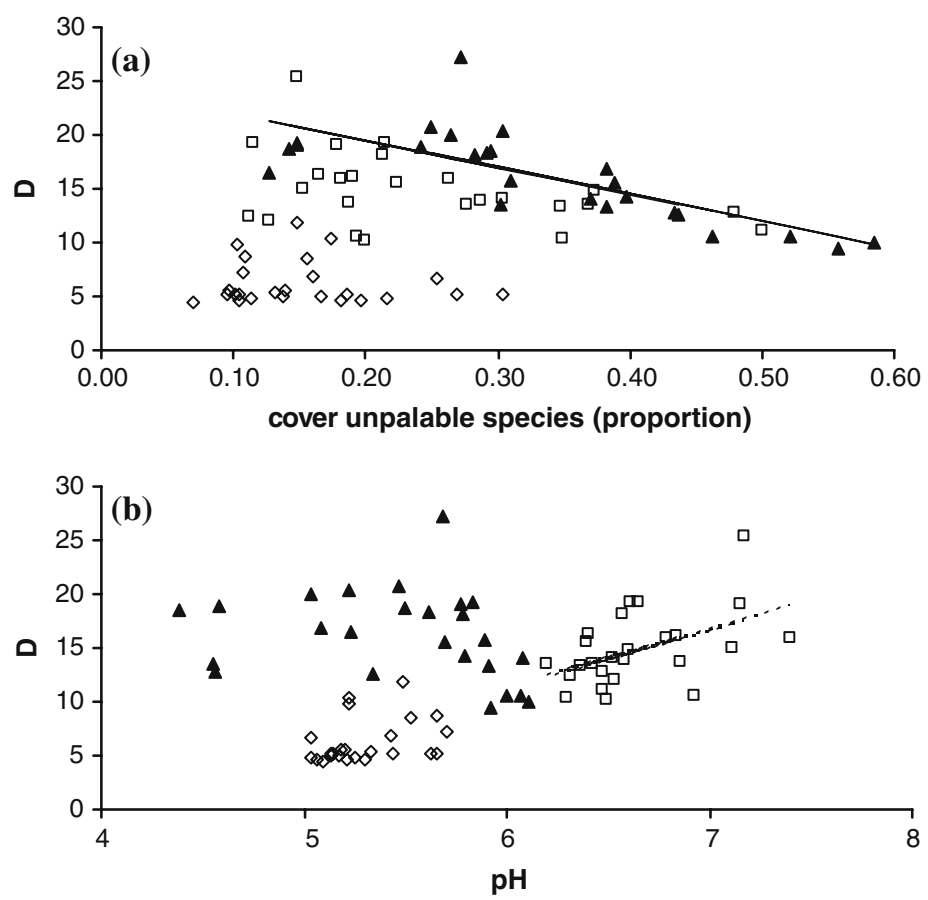

Figure 2. Relationship between Simpson's Diversity Index $(D)$ and (a) the abundance of unpalatable species, (b) $\mathrm{pH}$ in montane grasslands. Symbols and lines as in Figure 1.

affecting species richness and diversity covered N:P ratio, the relative abundance of unpalatable species and $\mathrm{pH}$. Furthermore, in one site none of the explanatory variables was related to species richness or diversity of the vegetation suggesting that still other factors may be important in this respect. This is perhaps not surprising given the large environmental heterogeneity in mountain habitats due to differences in, for instance, substrate, exposition, elevation or slope.

The abundance of unpalatable species significantly explained plant species richness and diversity in the Spittel Gantrisch site only. This site was characterized by the highest abundance of unpalatable species (Table 1, Figure 1b). Possibly, the range of abundances observed in the other two sites did not extend sufficiently into the high abundance range to be able to detect adverse effects. The plots were located randomly in each site so that representative samples of both species richness and unpalatable species abundance were taken. Our results therefore suggest that, although unpalatable plant species have the potential to suppress plant species richness, they rarely occur at densities high enough to actually do so.

The adverse effects of unpalatable species were probably mediated by competition for light. Most examined unpalatable species were tall species (e.g. 


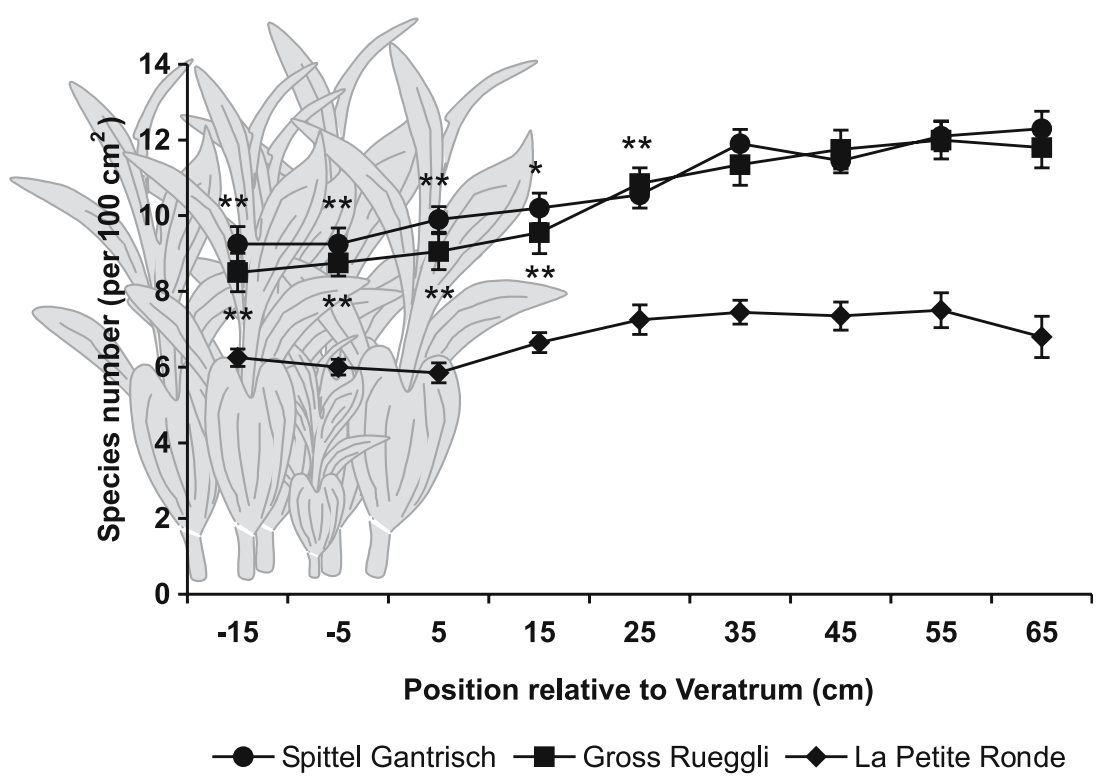

Figure 3. Mean plant species richness ( \pm s.e.) at increasing distances from the edge of patches of Veratrum album. Negative values indicate plots inside the Veratrum patches. Asterisks indicate significant differences from position $60-70 \mathrm{~cm},{ }^{*} p<0.05,{ }^{* *} p<0.01, n=20$. Diamonds, La Petite Ronde; squares, Gross Rüggli (lower asterisks); circles, Spittel Gantrisch (upper asterisks).

Veratrum album, Polygonum bistorta, Cirsium oleraceum, Ranunculus acris) that, given sufficient nutrient supply, can easily outshade co-occurring species. This is illustrated by the small-scale effects of Veratrum: in and near patches of Veratrum species richness was lower than in the open pasture. Our findings are corroborated by a recent study of Müller et al. (2003) in pastures between 1300 and $2100 \mathrm{~m}$ altitude in the Swiss Alps. They found that species that were correlated negatively with local plant species richness were mainly tall and unpalatable (Rumex alpinus, Senecio alpinus and Ranunculis acris). The growth strategy may also explain why negative effects only become apparent at very high densities (Figure 1b). Most unpalatable species have a clumped growth form and, once established, vegetative spread is restricted. Unless unpalatable species have been able to establish from seed at very high densities, plenty of niches will remain available for other species to persist. This would explain why Veratrum had negative effects on plant species richness at the small scale but not at larger scales. The limited adverse effects of unpalatable species contrasts with the severe negative effects that vegetatively spreading, turf-forming species such as grasses can have on plant species richness, for instance as a result of increased nutrient supply (Bobbink 1991).

Soil N:P ratio proved to be the most important factor, with highly significant and positive relationships with plant species richness in two out of three study 
sites. It is noteworthy that the ratio between total soil $\mathrm{N}$ and $\mathrm{P}$ had more descriptive power than either of the nutrients alone. For example, in the Gross Rüggli site, plant species richness was highly significantly related to soil N:P ratio $\left(t_{23}=4.22 ; p<0.001\right)$, whereas it was not significantly related to either soil $\mathrm{N}$ or soil $\mathrm{P}(p>0.10)$. In a study of 74 grassland plots, Braakhekke and Hooftman (1999) found the highest species richness at vegetation N:P ratios of $10-14$, with lower species richness at both higher and lower values. This may be explained by the absence of species adapted to $\mathrm{N}$ limitation (indicated by lower N:P ratios; Aerts et al. 1992; Shaver and Chapin 1995; Koerselman and Meuleman 1996) or P limitation (higher N:P ratios) in habitats where one of these nutrients is limiting (Braakhekke and Hooftman 1999; Aerts et al. 2003). In habitats where resources are balanced, both types of species may be able to persist. This hypothesis may therefore explain the positive relationship between soil N:P ratio and plant species richness in our study as N:P ratios were lower than 11 suggesting $\mathrm{N}$ limitation. The lack of any relationship between species richness and soil N:P ratio reported by Bedford et al. (1999) may have been due to the fact that the N:P ratios in their study ranged from 5 to 45 .

The soil nutrient levels encountered in the three fields corresponded to those previously observed in species-rich grasslands (Gough and Marrs 1990; Janssens et al. 1998; Köhler et al. 2001). Janssens et al. (1998) compared 281 different fields throughout Atlantic Europe and found total $\mathrm{N}$ to vary between 1 and $12 \mathrm{~g} / \mathrm{kg}$ dry soil. We found approximately the same range in just three fields (Table 1). The enormous small-scale spatial heterogeneity in nutrient supply that is present in montane pastures may be one of the explanations for the high species richness and diversity of these ecosystems.

\section{Implications for the conservation of plant species richness in montane pastures}

In Europe, montane species-rich pastures are manmade ecosystems and have evolved through centuries of extensive livestock grazing with no or very little external inputs. Due to the large environmental heterogeneity in montane habitats, both at the large scale (between sites) and the small scale (within sites), there is no single factor that has overriding effects on plant species richness. This contrasts with the situation in most lowland agricultural grasslands where usually the high productivity has overriding suppressive effects on plant species richness. Our results suggest that relaxation of the control of unpalatable weeds will not have immediate negative effects on plant species richness unless their abundance becomes very high. However, in areas where land abandonment is a problem, weeds may increase the likelihood that a field is being abandoned when a farmer considers them to affect the forage quality negatively. Indirectly, unpalatable species may therefore affect the diversity of montane grasslands as abandonment has clear negative effects on plant species richness (MacDonald et al. 2000; Dullinger et al. 2003). 
Our results further suggest that management that will increase the imbalance in resource supply will reduce plant species richness. Even moderate applications of artificial fertilizers may have serious repercussions on the botanical diversity of pastures as these fertilizers rarely supply nutrients in balanced proportions. Furthermore, effects of nutrient enrichment occur rapidly and it has proven extremely difficult to restore former species-rich grasslands once they have been eutrophicated (Bakker and Berendse 1999). It seems therefore most effective to focus initiatives to conserve species-rich montane pastures on the prevention of intensification of management.

\section{Acknowledgements}

We highly appreciate the help of Jakob Troxler and Bernard Jean-Gros with the site selection and of Jan van Walsem in the laboratory. We kindly thank Mr. Niederberger for his hospitality, allowing us to work on his field. Critical comments of Frank Berendse, Wim Braakhekke and Ragan Callaway on earlier drafts significantly improved the manuscript. This work was partially funded by the Swiss National Science Foundation through the National Centre of Competence in Research (NCCR) Plant Survival, and the National Research Programme 48 on Landscapes and Habitats of the Alps.

\section{References}

Aerts R., de Caluwe H. and Beltman B. 2003. Is the relation between nutrient supply and biodiversity co-determined by the type of nutrient limitation? Oikos 101: 489-498.

Aerts R., Wallen B. and Malmer N. 1992. Growth-limiting nutrients in Sphagnum-dominated bogs subject to low and high atmospheric nitrogen supply. J. Ecol. 80: 131-140.

Ammon H.U. and Müller-Schärer H. 1999. Prospects for combining biological weed control with integrated crop production systems, and with sensitive management of alpine pastures in Switzerland. Zeitschrift für Pflanzenkrankheiten und Pflanzenschutz 106: 213-220.

Augustine D.J. and McNaughton S.J. 1998. Ungulate effects on the functional species composition of plant communities: herbivore selectivity and plant tolerance. J. Wildlife Manage. 62: 1165-1183.

Bakker J.P. and Berendse F. 1999. Constraints in the restoration of ecological diversity in grassland and heathland communities. Trend. Ecol. Evol. 14: 63-68.

Bedford B.L., Wallbridge M.R. and Aldous A. 1999. Patterns in nutrient availability and plant diversity of temperate North American wetlands. Ecology 80: 2151-2169.

Berendse F. and Elberse W.Th. 1989. Competition and nutrient losses from the plant. In: Lambers H., Cambridge M.L., Konings H. and Pons T.L. (eds), Causes and Consequences of Variation in Growth Rate and Productivity of Higher Plants. Academic Publishing bv, The Hague, The Netherlands, pp. 269-284.

Bobbink R. 1991. Effects of nutrient enrichment in Dutch chalk grassland. J. Appl. Ecol. 28: 28 -41.

Braakhekke W.G. and Hooftman D.A.P. 1999. The resource balance hypothesis of plant species diversity in grassland. J. Veg. Sci. 10: 187-200.

Doree A. 1987. Le veratre ou ellebore blanc (Veratrum album L.). Proceedings of the 5ème réunion du sous-réeau FAO des herbages de montagne, Bled, Yugoslavia, pp. 1-6

Donald P.F., Green R.E. and Heath M.F. 2001. Agricultural intensification and the collapse of Europe's farmland bird populations. Proc. Roy. Soc., Lond. (B) 268: 25-29. 
Donald P.F., Pisano G., Rayment M.D. and Pain D.J. 2002. The common agricultural policy, EU enlargements and the conservation of Europe's farmland birds. Agric. Ecosyst. Environ. 89: 167-182.

Dullinger S., Dirnbock T., Greimler J. and Grabherr G. 2003. A resampling approach for evaluating effects of pasture abandonment on subalpine plant species diversity. J. Veg. Sci. 14: 243-252.

Edwards G.R. and Crawley M.J. 1999. Herbivores, seed banks and seedling recruitment in mesic grassland. J. Ecol. 87: 423-435.

EEA. 2004. High Nature Value Farmland - Characteristics, Trends and Policy Challenges. European Environment Agency, Copenhagen, Denmark.

GENSTAT 5 Committee of the Statistics Department. 1993. Genstat 5 release 3 reference manual. Oxford University Press, Oxford, The United Kingdom.

Gough L. and Grace J.B. 1998. Herbivore effects on plant species density at varying productivity levels. Ecology 79: 1586-1586.

Gough M.W. and Marrs R.H. 1990. A comparison of soil fertility between semi-natural and agricultural plant communities: implications for the creation of species-rich grassland on abandoned agricultural land. Biological Conservation 51: 83-96.

Grant S.A., Suckling D.E., Smith H.K., Torvell L., Forbes T.D.A. and Hodgson J. 1985. Comparative studies of the diet selection by sheep and cattle: the hill grasslands. J. Ecol. 73: 987-1004.

Houba V.J.G. and der Lee J.J. 1995. Soil and Plant Analysis, a Series of Syllabi Part 5B: Soil Analysis Procedures, Other Procedures. Department of Soil Science and Plant Nutrition, Agricultural University, Wageningen, The Netherlands.

Janssens F., Peeters A., Tallowin J.R.B., Bakker J.P., Bekker R.M., Fillat F. and Oomes M.J.M. 1998. Relationship between soil chemical factors and grassland diversity. Plant Soil 202: 69-78.

Kleijn D. and Steinger T. 2002. Contrasting effects of grazing and hay cutting on the spatial and genetic population structure of Veratrum album, an unpalatable, long-lived, clonal plant species. J. Ecol. 90: 360-370.

Koerselman W. and Meuleman A.F.M. 1996. The vegetation N:P ratio: a new tool to detect the nature of nutrient limitation. J. Appl. Ecol. 33: 1441-1450.

Köhler B., Ryser P., Güsewell S. and Gigon A. 2001. Nutrient availability and limitation in traditionally mown and in abandoned limestone grasslands: a bioassay experiment. Plant Soil 230: 323-332.

Lauber K. and Wagner G. 1998. Flora Helvetica. Haupt, Bern, Switzerland.

MacDonald D., Crabtree J.R., Weisinger G., Dax Y., Stamou N., Fleury P., Guttierez-Lazpita J. and Gibon A. 2000. Agricultural abandonment in mountain areas of Europe: environmental consequences and policy response. J. Environ. Manage. 59: 47-69.

Müller P., Güsewell S. and Edwards P.J. 2003. Einfluss von Boden und Bewirtschaftung auf die Artenvielfalt der Vegetation auf Alpweiden im Glarnerland. Botanica Helvetica 113: 15-36.

Proulx M. and Mazumder A. 1998. Reversal of grazing impact on plant species richness in nutrientpoor vs. nutrient-rich ecosystems. Ecology 79: 2581-2592.

Schläpfer F. and Fischer M. 1998. An isozyme study of clone diversity and relative importance of sexual and vegetative recruitment in the grass Brachypodium pinnatum. Ecography 21: 351-360.

Schaffner U., Kleijn D., Brown V. and Müller-Schärer H. 2001. Veratrum album L. in montane grasslands: a model system for implementing biological control in land management practices of high biodiversity habitats. Biocontrol News and Information 22: 19N-28N.

Shaver G.R. and Chapin F.S.III 1995. Long-term responses to factorial, NPK fertilizer by Alaskan wet and moist tundra sedge species. Ecography 18: 259-275.

Sokal R.R. and Rohlf F.J. 1995. Biometry. Freeman and Company, New York, US.

Spatz G. 1980. Succession patterns on mountain pastures. Vegetatio 43: 39-42.

Todd S.W. and Hoffman M.T. 1999. A fence-line contrast reveals effects of heavy grazing on plant diversity and community composition in Namaqualand, South Africa. Plant Ecol. 142: 169-178.

UN/ECE. 2003. Kyiv resolution on biodiversity. Fifth Ministerial Conference 'Environment for Europe', May 2003. Document ECE/CEP/108.United Nations, Economic Commission for Europe, Kyiv, Ukraine,, pp. 21-23 